\title{
Modeling the yield of hydrolysis process of leather shavings
}

\author{
Hana Vaskova ${ }^{1, *}$, and Pavel Kocurek ${ }^{1}$ \\ ${ }^{1}$ Tomas Bata University in Zlin, Faculty of Applied informatics, Department of Electronic and Measurements, 76005 Zlin, \\ Czech Republic
}

\begin{abstract}
In this paper the mathematical modeling of collagen hydrolyzate yield from shavings, a leather waste material, is dealt. Besides its function, leather industry is perceived as a consumer of resources and producer of pollutants. The process of alkaline enzymatic hydrolysis offers a reasonable method of processing part of solid waste arising from leather industry with the aim of further utilization of collagenous share. The model is based on the total mass and dry matter balances of technology and its individual components to optimize the hydrolysate yields. The results are visualised in 3D. The experimental laboratory data of alkaline enzymatic hydrolysis are used for comparison with the model and are discussed.
\end{abstract}

\section{Introduction}

The environmental protection is a topic attracting lot of attention. Attitudes are different. Different also in terms of what each individual can or wants to do and really does, and what is the matter of larger units, such as at the level of manufacturing industries. In each production, waste is generated.

A significant amount of waste arises annually from manufacturing sector. In this paper it is dealt with waste generated in leather industry. Leather products like footwear, clothing, handbags, wallets, fashion accessories, upholstery, etc. are among the objects of our everyday needs. However a way of conversion of rawhide to leather requires many treatment processes. The diversity and amounts of produced waste represent a serious problem. The production of $200 \mathrm{~kg}$ of leather requires $1000 \mathrm{~kg}$ of raw hides, i.e. the use of feedstock is only $20 \%$. From the input of $1000 \mathrm{~kg}$ about $250 \mathrm{~kg}$ of non-tanned waste, $200 \mathrm{~kg}$ of tanned wastes containing chromium is also produced [1]. A remaining share comprises modified solid waste and sludge. In the production of $200 \mathrm{~kg}$ of leather about $50,000 \mathrm{~kg}$ of waste water containing about $5 \mathrm{~kg}$ of chromium is generated [2].

Chrome-tanning is still the most common type of tanning worldwide. Complex salts of trivalent chromium effectively influence the desired functional properties of leather. The fibril-forming collagens are the major structural proteins of hides and skins. Salts of trivalent chromium stabilize a hide by crosslinking collagen fibres and supply required qualities. However, trivalent chromium contained in leather can be under various conditions in small amounts oxidized to another form hexavalent chromium [3]. Hexavalent chromium belongs among toxic elements and its salts are classified as carcinogen in the contrast to the trivalent form, which is benign, safe and largely beneficial [4]. Chromium is contained in solid waste and waste water. The degradation to toxic form can occur in the environment, e.g. during landfilling [5].

There are many aspects such as losses of collagen material or energy and chemical consumption requiring changes of attitude and optimization of both, production processes and waste processing. Despite growing demand for alternative methods of tanning, and there some existing e.g. [6], none has been a competitive replacement to such a large extend [7].

The existing methods of processing waste containing chromium are often based on separation of collagenous material and chromium share. This is done by hydrolytic reaction in alkaline or acidic medium. The protein is liquified and after further treatment can be applied in forms of gelatine or protein hydrolyzates. The further use of chromium sludge is not so successful. However, for example a by thermal decomposition a reduction of chrome cake amount can be reached [8]. Anyway it is still better solution to process at least a part of waste material.

Mathematical modeling gains a great importance for the analysis and prediction of the behaviour of processes and phenomena. It seems to be useful in the optimization of waste processing as well. Although the quality of the waste material varies according to sources and type, modeling may indicate the appropriate direction for efficient processing.

\section{Objective of the study}

The objective of this study is mathematical modeling of yield of collagenous hydrolyzate produced by alkaline enzymatic hydrolysis, based on the physico-chemical characteristics of the inputs and intermediates within the processing and comparing with real experimental laboratory data. 


\section{Dechromation process}

Hydrolysis of leather shavings in alkaline medium is used to obtain enzymatic hydrolyzate of collagen. The production system consists of three fundamental elements: reactor, filter and evaporator. When the desired degree of hydrolysis is reached, hot heterogeneous mixture is filtered and the resulting filtrate is transferred to an evaporator for increasing the concentration of hydrolysed substance.

\section{Mathematical model}

The physico-chemical processes occurring in the reactor can be described along with other mathematical relationships on the basis of the mass and mass fraction of dry matter. The assignments of physical quantities occurring in the model are listed in Table 1.

The yield of hydrolysates is closely related to the input materials parameters as well as the parameters of intermediates in the production process. The simulation calculations for the yield of final hydrolysates is based on mass and mass fraction of dry matter balances for the entire production system, its units and combination of these units. The balances are listed in the equations (1) (4).

Table 1. Assignments for the model.

\begin{tabular}{|c|c|c|}
\hline Designation & Quantity & Unit \\
\hline$m_{s}$ & $\begin{array}{c}\text { Mass of shavings } \\
\text { (feedstock) }\end{array}$ & $\mathrm{t}$ \\
\hline$m_{w}$ & $\begin{array}{l}\text { Mass of water } \\
\text { (feedstock) }\end{array}$ & $\mathrm{t}$ \\
\hline$m_{o b}$ & Mass of organic base & $\mathrm{t}$ \\
\hline$m_{m}$ & Mass of $\mathrm{MgO}$ & $\mathrm{t}$ \\
\hline$m_{f k}$ & Mass of filter cake & $\mathrm{t}$ \\
\hline$m_{f}$ & Mass of filtrate & $\mathrm{t}$ \\
\hline$m_{w w}$ & Mass of waste water & $\mathrm{t}$ \\
\hline$m_{p}$ & Mass of product & $\mathrm{t}$ \\
\hline$a_{s}$ & $\begin{array}{l}\text { Dry matter } \\
\text { of shavings }\end{array}$ & 1 \\
\hline$a_{f k}$ & $\begin{array}{l}\text { Dry matter } \\
\text { of filter cake }\end{array}$ & 1 \\
\hline$a_{f}$ & Dry matter of filtrate & 1 \\
\hline$a_{p}$ & Dry matter of product & 1 \\
\hline
\end{tabular}

Total mass balance of the whole system:

$$
m_{S}+m_{w}+m_{o b}+m_{m}=m_{f k}+m_{p}+m_{w w}
$$

Balance of the total dry matter of technology

$$
m_{S} a_{S}+m_{m}=m_{f k} a_{f k}+m_{p} a_{p}
$$

Mass balance of reactor and filter

$$
m_{S}+m_{w}+m_{o b}+m_{m}=m_{f k}+m_{f}
$$

Balance of dry matter of evaporator

$$
m_{f l} a_{f l}=m_{p} a_{p}
$$

The calculations are solved for the specific values given in Table 2. These values of mass fractions of dry matter in individual raw materials are considered to cover the range with higher probability of their achievement in the hydrolysis process. The amounts of feedstock were chosen for a real reactor in semiindustrial scale - 3 tons of leather waste material and 15 tons of water. Values of dry matters and mass rate of shavings and water are known from previous experiments. Varying value of dry matter of feedstock material due to various sources of leather waste, that also affects the filtrate, should be considered.

Masses $m_{f k}, m_{f}, m_{w}$ and $m_{p}$ represent unknown modeled quantities.

The objective is to gain as much product as it is economically profitable with the consideration of the main operating costs.

Table 2. Dry matter values.

\begin{tabular}{|c|c|}
\hline Quantity & Value \\
\hline$a_{s}$ & $0.20-0.80$ \\
\hline$a_{f k}$ & $0.10-0.50$ \\
\hline$a_{f}$ & 0.02 \\
\hline$a_{p}$ & 0.30 \\
\hline
\end{tabular}

\subsection{Outputs of the model}

Based on the equations (1) - (4), a 3D visualization of solution of the balance mathematical model was performed in software Wolfram Mathematica 9.

The product mass dependence on dry matter of shavings and filter cake is displayed in Fig. 1. Dependence of the product mass on the dry matter of filter cake and the water consumption for three specific dry matter values of the leather shavings in the range of $0.20-0.80$ is shown in Fig. 2. Also product mass 


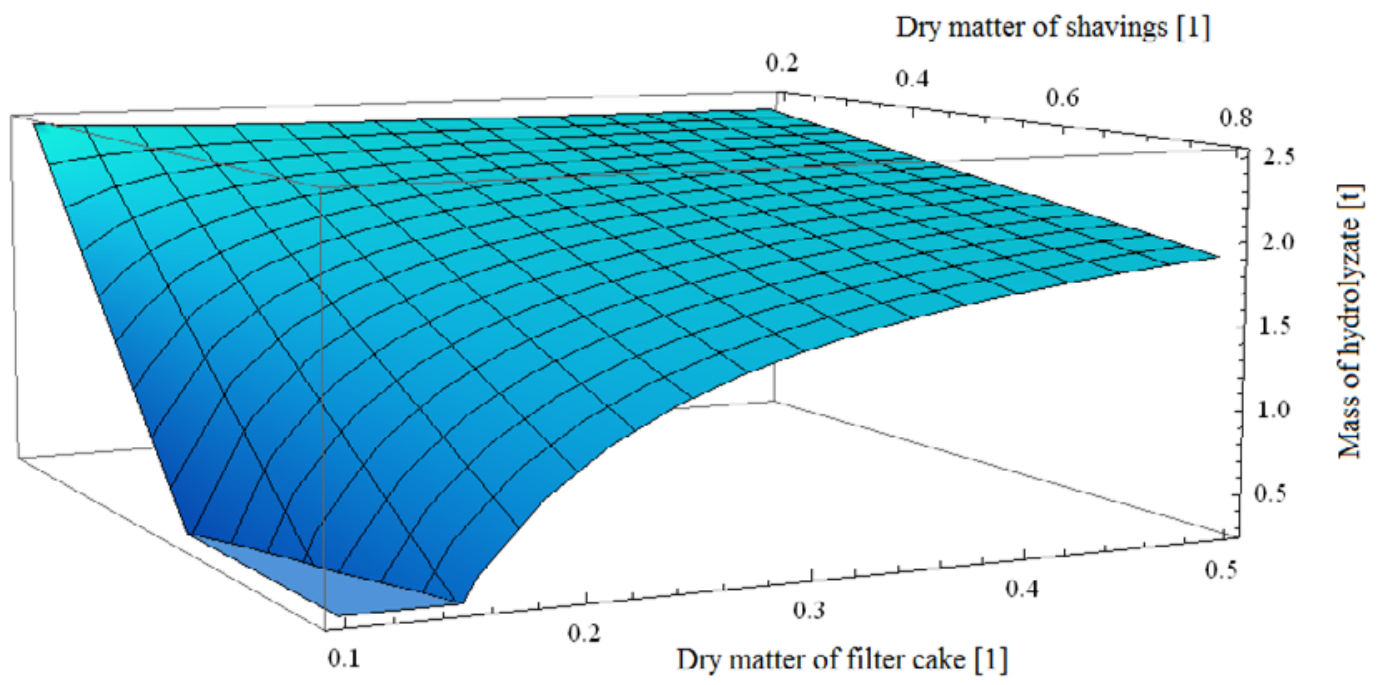

Fig. 1. 3D visualisation of product mass dependence on dry matter of shavings and filter cake.

dependence on dry matter of shavings and water consumption was dealt.

The amount of dry matter in the filter cake depends on the time of filtration and the consumption of pressure energy. As illustrated in Fig. 1., after reaching the value of the dry matter in filter cake approximately 0.3 , it is not effective to continue in hydrolysis reaction. Prolongation of the process has no significant effect on the yield of the product. Contrariwise, the energy consumption is higher and hence, the operational costs
[9], is increased.

In Fig. 2., 3D dependences of hydrolyzate yields on the dry matter of filter cake and the consumption of water for a specific mass of dry matter of leather shavings are displayed. Results indicate how the product yields develop in a range of dry masses of shavings. The most remarkable change occurs for lower values of dry matter of filter cake. Also the consumption of water for reaching the same product yield increase with the higher amount of dry matter in leather shavings.

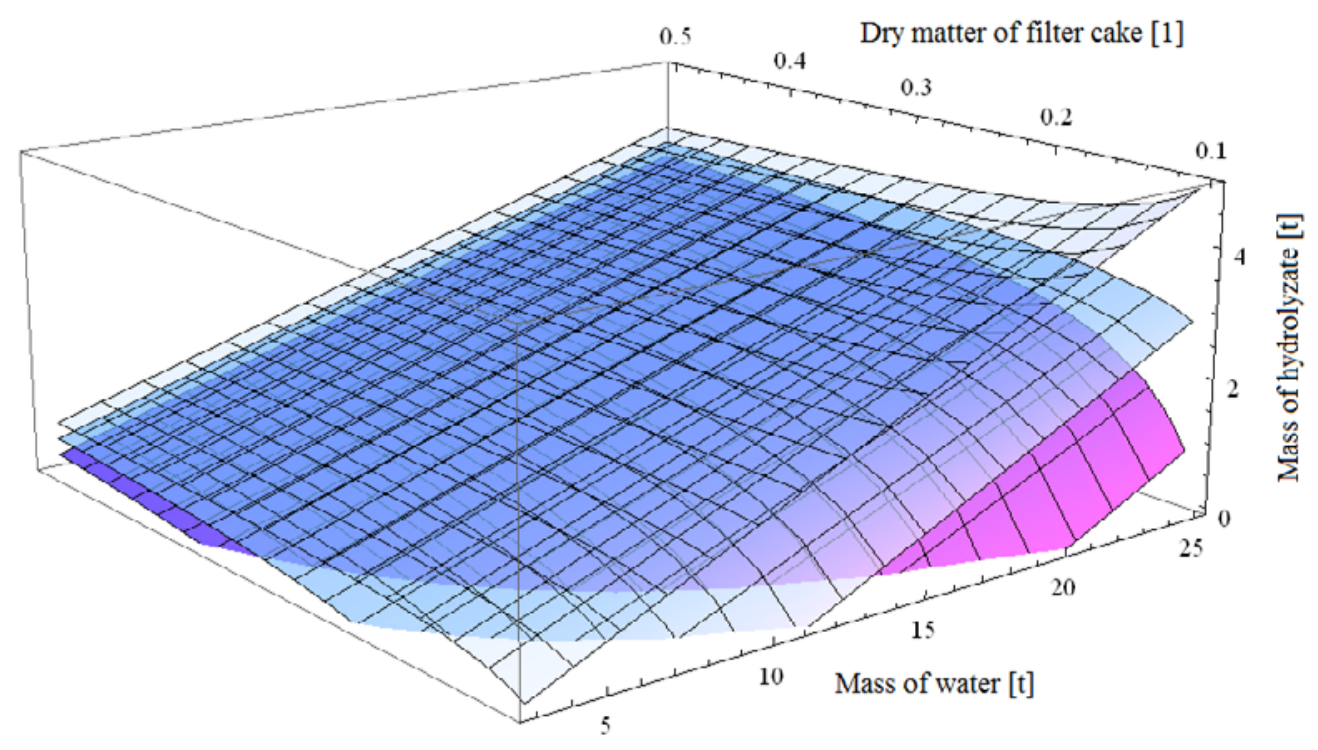

Fig. 2. 3D visualisation of dependence of product mass on the dry matter of filter cake and the consumption of water for constant mass of dry matter of chromium shavings 0.2 (upper), 0.5 (middle) and 0,8 (lower). 


\section{Experimental data}

\subsection{The experiment}

The experiment included the hydrolysis phase in the batch reactor and the subsequent filtration phase, all done under laboratory conditions. For the experiment leather shavings from chrome-tanned cattle hides from a local tannery were used. Hydrolysis was done in automatically controlled batch reactor in approximately quarter size of a pilot scale.

Firstly, a reaction mixture from chromium shavings and distilled water in the ratio of 1:5 was prepared. Magnesium oxide was added to reach optimal alkaline conditions. Process of alkalinization was completed after 2 days and was followed by gradual heating of the mixture for one hour up to $70{ }^{\circ} \mathrm{C}$. The $\mathrm{pH}$ was controlled and modified when necessary by cyklohexylamine to be in range 9-9.5 and Alcalase enzyme was added. The reaction mixture was hydrolysed for 4 hours, while stirred. Finally, after completion of the hydrolysis, the mixture was filtered through a fabric filter to separate the collagen hydrolysate from chromium cake.

The data obtained from experimental alkaline hydrolysis of shavings and filtration under laboratory conditions are shown in Table 3.

Table 3. Experimental data.

\begin{tabular}{|c|c|c|c|}
\hline & $\begin{array}{c}\text { Mass } \\
{[\mathbf{k g}]}\end{array}$ & $\begin{array}{c}\text { Dry } \\
\text { matter } \\
{[\mathbf{1}]}\end{array}$ & $\begin{array}{c}\text { Total } \\
\text { chromium } \\
\text { [g/kg of dry } \\
\text { matter] }\end{array}$ \\
\hline I & \multicolumn{3}{|l|}{} \\
\hline Shavings & 2.00 & 0.639 & 33.700 \\
\hline Water & 10.00 & 0 & - \\
\hline Filter cake & 6.12 & 0.178 & 44.450 \\
\hline Filtrate & 4.98 & 0.020 & 0.002 \\
\hline II & & & \\
\hline Shavings & 3.00 & 0.367 & 33.742 \\
\hline Water & 15.00 & 0 & - \\
\hline Filter cake & 6.04 & 0.176 & 33.137 \\
\hline Filtrate & 10.10 & 0.013 & 0.666 \\
\hline
\end{tabular}

\subsection{Comparison of the model and experimental laboratory data}

Because a real reactor was used, which is not apparently ideally isolated, the filtrate yield due to energy losses is lower than predicted. In the balance equations, losses during water evaporation are not included. However, the water content affects the dry matter and also the quantity of individual substances.

In the experiments performed, the energy losses are manifested by a difference in the weight of input and output substances of 7.5 and $10.3 \%$. Weight loss is mainly caused by water evaporation. The weights of the filtrate, regardless of loss, calculated from the mass balance, are $m_{f}=5.88 \mathrm{~kg}$ for experiment $\mathrm{I}$ and $m_{f}=11.96 \mathrm{~kg}$ for experiment II. These heat losses in terms of the amount of filtrate obtained in both cases make up about $15 \%$ difference. The experimental results indicate the further step of the study - that some coefficient of evaporation should be considered in the mathematical model, as nothing in the world is ideal.

\section{Conclusions}

Development of methods for safe, environmentally friendly and economically effective reduction of waste is demanded all over the world. Model dealing with the requirement of minimizing cost in the process of hydrolysis of leather shavings in terms of yield was presented. Optimization the processing approach of leather wastes is based on thorough analysis of technological operations and on design of mathematical model describing the mechanism of physico-chemical behaviour. Comparison of the model with experimental data shows the need to include, in particular, water loss due to the design of the reactor.

This work was supported by the Ministry of Education, Youth and Sports of the Czech Republic within the National Sustainability Programme project No. LO1303 (MSMT7778/2014).

\section{References}

1. S. Huffer, T. Taeger, JALCA, 99 424-428 (2004)

2. D. Janacova, V. Vasek, K. Kolomaznik et. al. Automatizace, regulace a procesy, 55-66 (2010)

3. K. Kolomazník, M. Adámek, I. Anděl, M. Uhlírová, J. Hazard. Mater. 160 514-520 (2008)

4. X. Hang, X. Zhang, X. Wang, L. Jin, Z. Yang, C. Jiang, Q. Chen, BMC Public Health. 11 224-232 (2011)

5. J. Lopez-Luna, M. C. Gonzalez-Chavez, F. J. Esparza-Garcia, R. Rodriguez-Vazquez, . Hazard. Mater. 163 829-834 (2009)

6. M. Crudu, V. Deselnicu, DC Deselnicu, L. Albu, Waste Manage 34 1806-1814 (2014)

7. Proposal for a restriction. Danish Environmental Protection Agency [online] (2012)

8. P. Kocurek, K. Kolomazník, M. Bařinová, J. Hendrych, Waste Manage. Res 35 444-449 (2017)

9. H. Vašková, K. Kolomazník, ICCC. (to be published) 